\title{
Cytotoxic Activities of Phytochemicals and Cure for Lifestyle Deseases (A Promising Area in Future Research)
}

\section{Raga R.}

\section{${ }^{\mathrm{I}}$ Post Graduate in Applied} Plant Science, Faculty of Mercury Medical Entrance Academy, Thrissur, Kerala

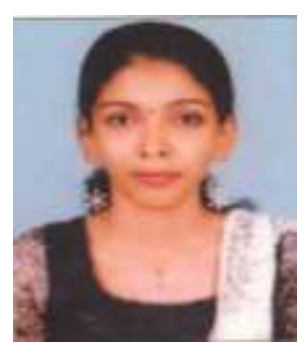

Corresponding author:

Raga R.

ragarmenon@gmail.com

Received: September 24, 2017

Revised: November 29, 2017

Published: December 30, 2017

\begin{abstract}
Cytotoxicity is the quality of being toxic to cells which is a rapid standardized test that is very sensitive and an inexpensive way to determine if the materials contain significant quantities of harmful extractables and their effect on cellular components. Cytotoxicity of plant extracts can indicate their antitumour and anticancerous potentials, which may help in developing new drugs. Cytotoxicity of Callistemon viminalis leaf extracts were analyzed in Allium cepa root apical meristem as it has an excellent correlation with mammalian genetic system. The potential cytotoxicity of the chemical compounds present in these leaf extracts can be used for chemoprevention which is an active cancer preventive strategy to inhibit or delay carcinogenesis using naturally occurring biomolecules. It is regarded as one of the most promising avenues for cancer control.
\end{abstract}

Keywords- Cytotoxicity, Anticancerous, Chemoprevention. 


\section{INTRODUCTION}

The world of fragrance is highly varied and fascinating. Of about 18000 plants species in India, about 15000 species are aromatic, producing essential oil in one or another plant organ; may be roots, leaves , flowers and sometimes bark and wood. They are so diverse in their aroma owing to characteristic volatile oil constituents (Skaria et al., 2007). In recent years, there has been a tremendous growth of interest in plant based drugs, pharmaceuticals, perfumery products and fragrances and natural colours in the world. Chemically depending on the active principles, plants may have alkaloids, glycosides, steroids or other group of compounds which may have marked pharmaceutical activities such as anticancerous, antimalarial, anthelminthic etc. Nature has enormous diversity of medicinal plants. Herbal medicine is used by $75-80 \%$ of the world population mainly in the developing countries for primary health care (Kamboj, 2000). Plants have always been a common medicament either in the form of traditional preparations or as pure active principles. According to WHO the use of herbal remedies throughout the world exceeds that of the conventional drugs by 2-3 times. In a survey conducted by WHO, it has been estimated that $30 \%$ or more than 4000 million inhabitants of the world rely chiefly on traditional medicines for their primary health care needs. This is because of their better cultural acceptability, better compatability with the human body and lesser side effects.

Cancer is a leading cause of death worldwide, accounting for 8.8 million deaths in 2015. Globally, nearly 1 in 6 deaths is due to cancer. The most common causes of cancer death are cancers of

- $\quad$ Lung (1.69 million deaths)

- $\quad$ Liver (788 000 deaths)

- $\quad$ Colorectal (774 000 deaths)

- $\quad$ Stomach (754 000 deaths)
- $\quad$ Breast (571 000 deaths)

Cancer arises from the transformation of normal cells into tumour cells in a multistage process that generally progresses from a pre-cancerous lesion to a malignant tumour. These changes are the result of the interaction between a person's genetic factors and 3 categories of external agents including

- Physical carcinogens such as ultraviolet and ionizing radiations

- Chemical carcinogens such as asbestos, components of tobacco smoke, aflatoxins (a food contaminant), and arsenic (a drinking water contaminant) and

- Biological carcinogens such as infections from certain viruses, bacteria and other parasites.

Evidences indicate that tumorigenesis is a multistep process which involves the progressive transformation of normal cells to highly malignant derivatives. The economic impact of cancer is significant and is increasing. India is likely to have over 17.3 lakh new cases of cancer and over 8.8 lakh deaths due to the disease by 2020 with cancers of breast, lung and cervix topping the list. Data by Indian Council of Medical Research (ICMR) in 2016 revealed that only 12.5 per cent of patients come for treatment in early stages of the disease. Among females, breast cancer topped the list and among males mouth cancer, the study said. The northeast reported the highest number of cancer cases in both males and females. Aizawl district in Mizoram reported the highest number of cases among males while Papumpare district in Arunachal Pradesh recorded the highest number among females.

It seems quite obvious that it is the best time for large scale implementation of cancer chemoprevention as a therapeutic strategy. The lack of scientific and chemical data in support of better 
understandings of the efficacy and safety of the herbal drugs has become the major encumbrance to the use of traditional herbal preparations. Hence it is necessary to conduct more chemical and pharmacological studies at molecular level to investigate untapped potential of the herbal drugs. Chemopreventive phytochemicals would provide potential opportunities for future design of chemo-preventive agents based on molecular targeting. Cytotoxic activity of the leaf extract of Callistemon viminalis on Allium cepa root apical meristem was evaluated in the present study. Decrease in the mitotic index as a result of treatment with a particular substance shows its ability to kill actively dividing cells

(Tajo and Thoppil, 1998).This clearly indicates that the potentiality of that particular compound to be used as an anticancer chemotherapeutic agent.

\section{MATERIALS AND METHODS}

Cytotoxicity of Callistemon viminalis (Sol. Ex Gaertn) G. Don belonging to the family of Myrtaceae was selected as the plant material for the present study. The cytotoxicity of leaf extracts were analyzed in Allium cepa root apical meristem as it has an excellent correlation with mammalian genetic system. The healthy and uniform sized bulbs of Allium cepa were purchased from the local market, selected and washed in distilled water, planted in pure sandy soil and allowed the roots to sprout out. Aqueous extracts having both the polar and non polar compounds were prepared from the fresh leaves with the help of mortar and pestle. Different concentrations of the extracts $(\mathrm{w} / \mathrm{v})$ viz., $0.01,0.02,0.05$ and $0.1 \%$ were prepared in distilled water. Germinated bulbs with healthy roots were collected at the time of peak mitotic activity (9:30 a.m. - 10 a.m.) and treated with different concentrations of extract taken in bottles. Root tips were cut from few samples of each concentration at different time intervals such as $1 / 2 \mathrm{hr}$, $1 \mathrm{hr}, 2 \mathrm{hr}$ and $3 \mathrm{hr}$, washed thoroughly with distilled water and fixed in Carnoy's fluid. Mitotic squash experiments were conducted with the help of improved techniques (Sharma and Sharma, 1990). Control experiments were also done by immersing roots tips with distilled water at different time intervals of $1 / 2 \mathrm{hr}, 1 \mathrm{hr}, 2 \mathrm{hr}$ and $3 \mathrm{hr}$.

Mitotic index (\%) and abnormality percentage were calculated using the following formulae:

\section{Mitotic index $(\%)=$ \\ Number of dividing cells $\times 100$ Total number of cells}

\section{Abnormality = \\ Number of abnormal cells $\times 100$ Total number of cells}

All the slides were scanned under Nikon Eclipse E 400 Microscope, tabulated and photomicrographs were taken with the attached Nikon Digital Camera (Model D x M 1200F).

\section{RESULTS AND DISCUSSION}

Cytotoxic activity of leaf extract of Callistemon viminalis was analyzed in the present study. It was revealed that the extract is highly cytotoxic and considerable amount of abnormalities along with mitotic inhibition was recorded as a result of treatment in Allium cepa root tip meristematic cells with leaf extracts having both polar and non polar compounds (Table 2). The treatments showed many clastogenic and non clastogenic abnormalities. The major clastogenic abnormalities observed include chromatin erosion, 
nuclear lesion, ring chromosome, chromosome stickiness, abnormally enlarged nucleus at interphase, chromosome bridges, chromosome fragmentation, chromosome disintegration, pulverized chromatin, giant cells etc. The non clastogenic abnormalities include ball metaphase, stellate metaphase, polyploidy, Cmetaphase, laggard formation, micronuclei, divergent movement of chromosomes at anaphase, abnormal association of chromosomes etc. Mitotic indices of the various treatments were found to be less than that of control (Table 1).

$$
\text { Plant derived }
$$
compounds are used in traditional system of medicine for the treatment of different ailments. The cytotoxic potential of these extracts can be revealed using Allium test. Chromosomal aberrations have been considered as reliable indicators of mutagenic acitivity (Mohandas and Grant, 1972). Grant (1978) pointed out that plant chromosomes are sensitive indicators to environmental pollutants and thus higher plant systems appear to be excellent indicator of cytotoxic, cytogenetic and mutagenic effects of natural or environmental mutagens. Mitosis was found to be normal when Allium cepa root tip meristematic cells were treated with distilled water (control) which clearly showed $2 \mathrm{n}=16$ chromosomes at metaphase. A wide spectrum of abnormalities were recorded after treating with aqueous leaf extracts of Callistemon of various concentrations. The treatment with aqueous leaf extracts not only brought down the frequency of dividing cells but also produced a good number of anomalies in the mitotic cells. With a few exceptions, the abnormality percentage showed a direct relationship with the increase in treatment time. The cytotoxic chemicals act on mitotic cells in three different manners (Ray and Barman, 1987).

- Pre-prophase inhibition

- Inhibition of mitotic spindle formation and orientation, compounds being termed as mitoclastic agents

- Inhibition of cell plate and cell wall formation between daughter nuclei resulting in binucleate and multinucleate cells.

Different kinds of aberrations were classified into clastogenic aberrations attributable to the direct action in chromosomes and non clastogenic or physiological aberrations attributable to spindle abnormalities. The lowering of mitotic index may be due to the inhibition of DNA synthesis at $\mathrm{S}$ phase (Sudhakar et al., 2001)

TABLE-1: Consolidated data of mitotic divisional stages of Allium cepa root tip cells and mitotic index $(\%)$ in distilled water in different time periods

\begin{tabular}{|c|c|c|c|c|}
\hline Treatment time & $\mathbf{1} \mathbf{2} \mathbf{h}$ & $\mathbf{1 h}$ & $\mathbf{2 h}$ & $\mathbf{3 h}$ \\
\hline Total cells & 1102 & 1248 & 1040 & 1171 \\
\hline Prophase & 733 & 855 & 727 & 879 \\
\hline Metaphase & 22 & 56 & 43 & 38 \\
\hline Anaphase & 25 & 40 & 31 & 23 \\
\hline Telophase & 16 & 26 & 20 & 22 \\
\hline Cytokinesis & 7 & 26 & 20 & 22 \\
\hline Mitotic index & 72.82 & 78.27 & 80.81 & 82.08 \\
\hline
\end{tabular}


TABLE -2: Summary of cytotoxic activity of leaf extract (polar +non polar) on Allium cepa root tip cells

\begin{tabular}{|c|c|c|c|}
\hline Concentration & Time & Mitotic Index & Abnormality \\
\hline 0.1 & $1 / 2$ & 30.36 & 54.81 \\
0.1 & 1 & 29.98 & 50.42 \\
0.1 & 2 & 31.83 & 74.60 \\
0.1 & 3 & 33.83 & 77.72 \\
\hline 0.05 & $1 / 2$ & 29.20 & 48.75 \\
0.05 & 1 & 25.16 & 50.01 \\
0.05 & 2 & 36.68 & 74.16 \\
0.05 & 3 & 40.09 & 75.01 \\
\hline 0.02 & $1 / 2$ & 38.21 & 68.59 \\
0.02 & 1 & 44.71 & 75.70 \\
0.02 & 2 & 39.13 & 72.38 \\
0.02 & 3 & 48.23 & 75.70 \\
\hline 0.01 & $1 / 2$ & 47.00 & 73.65 \\
0.01 & 1 & 47.32 & 74.61 \\
0.01 & 2 & 35.51 & 74.55 \\
0.01 & 3 & 41.48 & 76.30 \\
\hline
\end{tabular}

\section{CONCLUSION}

Callistemon viminalis, an aromatic shrub of Myrtaceae was selected for the present study. It is native to the states of South Wales and Queensland in Australia where it often occurs along watercourses. The leaves of this plant were collected and a crude extract was prepared. The root tips of Allium cepa were used for testing cytotoxicity using different concentrations of extracts at different time intervals. Both clastogenic and non clastogenic abnormalities were noticed after treating leaf extracts on Allium cepa root tip cells. When compared with control experiments mitotic index showed a much greater decrease in root tip cells treated with aqueous leaf extract. In control experiments no anomaly in cell division was noted where as in root tip cells treated with aqueous extracts larger number of anomalies in all the stages of mitosis were noted. Thus from the results of these investigations it is suggested that the crude extract of $C$. viminalis may be used as an anti tumour promoting substance or for the production of therapeutic drugs for curing cancer. Moreover various compounds in the essential oil of the plant studied were found to have antifungal properties (Fontenella et al., 2006; Singh et al., 2000). Hence the extract of Callistemon viminalis which cause damage on Allium cepa root meristems even at low concentrations could be effectively exploited for formulating potential, eco friendly and biodegradable fungicides too.

\section{REFERENCES}

1. Fontenella, R.O.S., Morais, S.M., Brito, E.H.S., Brilhante, R.S.N., 
Corderiro, R. A., Nascimento, N.R.F., Kerrntopf, M. R., Sidrim, J.J.C. and Rocha M.F.G. (2006) Antifungal activities of essential oil of Croton species from Brazilian Catinga Biome. J. Appl. Microbiol. 104: 1383-1390.

2. Grant, W.F. (1978) Chromosomal aberration in plants as monitoring system. Environ. Hlth. Persp.27:347351.

3. Kamboj, V. P. (2000). Herbal Medicine. Curr. Sci. 78:35-39.

4. Mohandas, T and Grant, W.F. (1972) Cytogenetic effect of 2, 4-D and amitrol in relation to nuclear volume and DNA content in some higher plants. Can. J. Genetic. Cyto.14:773778.

5. Ray, M and Barman, A. (1987) Effect of industrial waste on root meristematic cells of Allium sativum $\mathrm{L}$. Phytomorphology 37: 359-364.

6. Sharma, A. K. and Sharma, A. (1990) Chromosome techniques- Theory and practice, $3^{\text {rd }}$ ed, Butter Worths, London.

7. Singh, G., Kapoor, I. P. S., Singh, O. P. Rao, G. P., Prasad. Y.R., Leciercq, P. A. and Klonkby, N. (2000). Studies on essential oils. Part: 28. Chemical composition, antifungal and insecticidal activities of rhizome volatile oils of Homalomena aromatica Schot. Flavour and Fragrance Journal 15:278-280.

8. Skaria, P.B., Joy, P. P., Mathew, S., Mathew, G., Joseph, A. and Joseph, R. (2007). History, importance and scope of aromatic plants. In: Aromatic Plants by K. V. Peter(ed.). NewDelhi, pp.1-4.

9. Sudhakar, R., Ning Gaida, K.N. and Venu, G. (2001). Mitotic abnormalities induced by silk dyeing industry effluents. Cytologia 66:236- 239.

10. Tajo, A. and Thoppil, J. E. (1998). Cytotoxic properties of Ocimum americanum L. Bull. Pure Appl. Sci. 17B: 49-53. 